\title{
Demographic and academic characteristics that contribute to burnout occurrence in nursing students - Analytic study
}

Rodrigo Marques da Silva*1, Luis Felipe Dias Lopes², Carmem Lúcia Colomé Beck³ , Eliane da Silva Grazziano ${ }^{4}$, Ana Lucia Siqueira Costa ${ }^{5}$, Victor Cauê Lopes ${ }^{6}$

${ }^{1}$ Faculty of Sciences and Education Sena Aires, Valparaíso de Goiás, GO, Brazil

${ }^{2}$ Administrative Sciences Department, Public University of Santa Maria (UFSM), Santa Maria, RS, Brazil

${ }^{3}$ Federal University of Santa Maria (UFSM), Santa Maria, Rio Grande do Sul, Brazil

${ }^{4}$ Federal university of São Carlos(UFSCAR), São Carlos, São Paulo, Brazil

${ }^{5}$ Department of Medical-Surgical Nursing, School of Nursing, University of São Paulo, São Paulo, SP, Brazil

${ }^{6}$ Nursing Department, Juinense's Association of Higher Education, Juina, Mato Grosso, Brazil

Received: December 19, 2017

DOI: $10.5430 /$ jnep.v8n8p28
Accepted: February 22, 2018

Online Published: March 22, 2018

\begin{abstract}
Objective: Several features, such as workload, irregular practice of sports, and work experiences may contribute to the Burnout However, although different investigations have assessed the associations between demographic and academic characteristics and Burnout across different countries, few studies were conducted in Brazil, especially with nursing students. So, we assessed the association of demographic and academic variables to Burnout occurrence in nursing students.

Methods: This is a quantitative, analytical and cross-sectional study. We applied a Form to demographic and academic characterization and the Maslach Burnout Inventory in 570 nursing students between April 2011 and March 2012. To compare the occurrence of Burnout and of its subscales regarding to sociodemographic and academic variables, we used the Chi-Square test and the Fisher exact test (Tables $2 \times 2$ ), $p<.05$. The Ethics Research Committee at the University approved this project under protocol No. 0380.0.243.000-10.

Results: Burnout occurrence is higher among students enrolled in first semester, who attend 10 disciplines, without thoughts of leaving the course and who has no job activity. The high Emotional Exhaustion and low Professional Efficacy predominate among unemployed students, and who never thought in leaving the course. The high Cynicism predominated among students aged 20-24 years, enrolled in first semester, who does not work and without experience in healthcare.

Conclusions: Few demographic and academic characteristics contribute to Burnout occurrence in nursing students, raising the need of interventions to relieve stress in this population.
\end{abstract}

Key Words: Nursing, Burnout, Professional, Stress, Psychological, Students, Nursing, Analytic epidemiology

\section{INTRODUCTION}

In Brazil, becoming a nurse requires a four or five-year nursing degree. In a four-year program, the first three semesters are composed for basic disciplines - biology, anatomy, physiology, patology, etc. The next three semesters are made by nursing disciplines-ethics in nursing, adult health nursing,

*Correspondence: Rodrigo Marques da Silva; Email: marques-sm@ @otmail.com; Address: Valparaíso de Goiás, Goiás, Brazil. 
pediatrics, etc., and the last year involves the nursing internship. So, when initiating a nursing undergraduate degree, the student starts to live with a different environment from that known in high school. It happens because the autonomy in the seek for knowledge is stimulated; and there is the need to perform different disciplines, especially in the first semester, which implies a considerable number of tests, exams and academic papers. ${ }^{[1-3]}$ Consequently, there is a greater activities load and less time available for friends, family and leisure. So, the time management is necessary in order to the student has a good performance in college and a satisfactory life quality. ${ }^{[1,4,5]}$ Also, nursing students live with seriously ill patients, with death and suffering of others; need to relate with health professionals, colleagues and teachers; and they have to meet the technical and scientific requirements at each course stage and internship field/practice classes. ${ }^{[1-5]}$ Besides, students need to establish relations between the theoretical assumptions and professional practice during the course, which often raises uncertainty and doubt. ${ }^{[1-5]}$

In this sense, the nursing education presents several situations which can be evaluated as stressful and lead the nursing students to stress. This phenomenon is defined, for the university environment, as a set of reactions that occurs when the curricular requirements exceed the capabilities or adaptive resources of the student. ${ }^{[6]}$ Moreover, the stress occurrence is secondary to cognitive assessment, i.e., the individual interprets the situations coming from the internal or external environment in different evaluative categories and defines them as a threat, a challenge or not relevant. ${ }^{[7]}$ When they are defined as a threat or as a challenge, the stress and its consequences to life and health of the college students are possible.

Thus, as stress outcomes to health of the undergraduate and postgraduate students, we stand out: the decrease of academic performance and of patient satisfaction, ${ }^{[8]}$ the increase of Depressive Symptoms, ${ }^{[9,10]}$ and decrease of self-esteem levels. ${ }^{[11,12]}$ Moreover, international studies have been found a significant relationship between stress and Burnout Syndrome (BS) occurrence among college students. ${ }^{[8,13]}$

Concerning this Syndrome, it occurs when the individual use strategies to cope with the stressor and they are not effective for this aim. Thus, the stressor remains, which may lead to chronic stress and, consequently, to Burnout. ${ }^{[14]}$ The BS features are: Emotional Exhaustion- feelings of being exhausted due to study requirements; Cynicism-cynical and detached attitude regarding to study; and Professional Inefficacy-a perception of incompetency as student. ${ }^{[14]}$ In this context, researchers have found $48.6 \%$ of medicine students from Washington ${ }^{[15]}$ and $17 \%$ of dental students ${ }^{[16]}$

Published by Sciedu Press from São Paulo with Burnout. It confirms the BS occurrence among college students.

It is already known that several features, such as the activity overload, irregular or absence of sports practices and of leisure activities, the time spent to get to institution, employment contracts and work experience may contribute to the Burnout occurrence. Thus, investigations have been analyzed the associations between sociodemographic and academic characteristics and the BS in different countries. ${ }^{[17]}$ In Brazil, according to researchers, few studies analyze the linkages between characteristics and Burnout, and, according to integrative review, there is no study developed among nursing students. ${ }^{[17,18]}$

Based on foregoing and on the fact of teaching environment established in the nursing degrees may be evaluated as stressor by students, which, in long-term, may lead to Burnout, we defend the following hypothesis: the sociodemographic and academic characteristics contribute to the BS occurrence in nursing students. Then, the aim of this investigation was to compare the BS occurrence regarding to sociodemographic and academic characteristics of nursing students.

\section{MATERials AND MethodS}

This is an analytical, cross-sectional and quantitative study, conducted in three Brazilian Higher Education Institutions (HEIs). We included students of nursing undergraduate programs of the three HEIs, correctly enrolled from 1st to 8th semester of these respective courses, aged over 18 years. We excluded students not enrolled in non-nursing disciplines, which during data collection period would not conclude the curriculum for exceeding time limit of each school, who were not present on data collection day and who were in exchange.

Data were collected between April 2011 and March 2012. Students were approached in classroom, after a previous scheduling with the teacher of each discipline, through meetings or, when necessary, individually. From 732 students taking the nursing degree, 14 were not enrolled in vocational disciplines cycle, three would not conclude curriculum for exceeding the time limit of these institutions, 91 did not attend the meetings, three were in exchange, four was aged under 18 years, 34 did not return the instruments to the researchers and four authored the investigation, which summed 153 exclusions. Also, over $90 \%$ of instruments' items were not filled for one student; and eight of them refused to participate. Therefore, the access population of this study was composed by 570 nursing students according to the inclusion and exclusion criteria defined.

We gathered the data with the next self-applied instruments: 
a form with sociodemographic information and the Maslach Burnout Inventory-Student Survey (MBI-SS). These instruments were applied to the participants who voluntarily agreed to participate in the study after signature of Free and Informed Consent Form.

The form of sociodemographic and academic characterization was composed for the following demographic variables: date of birth, number of children, sex, marital status, who students live with, participation in sports, participation in leisure activities. The academic variables included: time spent to get in college, number of disciplines taken in the current semester, daily study time, semester credit hours; time devoted to study/research group; semester, year of course commencement, attendance of research/study groups, scientific initiation scholarship, satisfaction with the course, professional experience in health area, another college degree, interest of dropping the course and work status (employed or unemployed). MBI-SS-translated and adapted to Brazilian culture in 2006-measure the Burnout occurrence in college students, i.e., how training is experienced for students. It is organized in three conceptual subscales-Emotional Exhaustion (EE), Cynicism (CY) and Professional Efficacy(PE) ${ }^{[19]}$ and contains 15 items whose scale response is presented in a seven-point Likert scale, ranging from: zero-"never", one-“at least one time a year", two-"a few times a month or less", three -"a few times a month", four-"once a week", five-"a few times a week", six-"Everyday". The items are allocated among subscales as follows: Emotional Exhaustion (Items 1, 4, 6, 8, 12), Cynicism (items: 2, 9, 10, 14) and Professional Efficacy (Items 3, 5, 7, 11, 13, 15). ${ }^{[19]}$

For MBI-SS analysis, we identified the levels of Emotional Exhaustion, of Cynicism and of Professional Efficacy presented by students through a standardized score. Thus, score was calculated by each MBI-SS subscale through the sum of $p$ values answered, excluding zeros and, from this resultant value, we subtracted the sum of possible minimum values for each subscale/domain. Then, the resultant value was divided by the difference between sum of maximum values $\mathrm{p}$ and sum of possible minimum values in the referred subscale/domain. From the final score, we identified the level of Emotional Exhaustion, Cynicism and Professional Efficacy of students, as follows: students with scores under or equal to $50 \%$ were considered with low level in the subscale. Those individuals scored over $50 \%$, were defined as high level in the subscale. Thus, when this association was high level of Emotional Exhaustion, high level of Cynicism and low level of Professional Efficacy, the student was considered to be experiencing BS. ${ }^{[19]}$ We stand out that the Professional Efficacy's items present an inverse scale. So, higher values $\mathrm{p}$ assigned to items result in lower feeling of Professional
Effectiveness. ${ }^{[19]}$

We created a database in Excel (Office 2007) for data organization and we used the Statistical Analysis System (SAS) (Version 9.01) and the Statistica (Version 9.01) for data analysis. To compare the occurrence of Burnout and of its subscales regarding to sociodemographic and academic variables, we used the Chi-Square test and the Fisher exact test (Tables $2 \times 2$ ). When the $p$ value was $<.05$, the results were considered statistically significant. We assessed the MBI-SS' internal consistency trough the Cronbach's Alpha.

The Ethics Research Committee at the University placed on South of Brazil approved this research project under the protocol (protocol No. 0380.0.243.000-10). Besides, an amendment to expand data collection for other schools was also requested and we obtained approval from Committee of the institution above. In order to meet the Brazilian National Health Council's guidelines, as established for studies involving human subjects, the participants voluntarily consented to participate in the study by signing two copies of free and informed consent forms (one for the participant and another for the researcher), after being informed of the study's objectives.

\section{RESUltS}

The Cronbach's alpha for the MBI-SS (15 items) was 0.596. Its subscales have shown the following values of Alpha: 0.769-Emotional Exhaustion; 0.623-Cynicism; and 0.612Professional Efficacy. These values are sufficient to attest to the instrument's satisfactory internal reliability for the population of this study. ${ }^{[20]}$

Concerning the sociodemographic data, there was a predominance of female students $(84,21 \%)$, aged between 20 and 24 years $(47,37 \%)$, single $(74,39 \%)$, without children $(81,5 \%)$ and who living with family $(75,57 \%)$. Minimum and maximum values, mean and standard deviations for the MBI-SS among nursing students are presented in Table 1.

Table 1. Minimum and maximum values, mean and standard deviations for the MBI-SS among nursing students. Rio Grande do Sul, Brazil, 2013

\begin{tabular}{lllll}
\hline Instrument & Mean & SD* & Minimum & Maximum \\
\hline MBI-SS & & & & \\
15 items & 2.51 & 0.79 & 0.40 & 4.87 \\
Emotional Exhaustion & 3.57 & 1.31 & 0.00 & 6.00 \\
Cynicism & 1.78 & 1.29 & 0.00 & 5.75 \\
Professional Efficacy & 2.12 & 0.82 & 0.83 & 5.67 \\
\hline *Standard Deviation & & & &
\end{tabular}

*Standard Deviation

Regarding to differences between BS occurrence and sociodemographic and academic variables, the significant re- 
sults among at least one group of variables will be presented in this investigation. Thus, we verify that, among students with $\mathrm{BS}$, predominate those enrolled in the first semester (7.37\%; $p=.01)$ and who perform 10 disciplines $(11.40 \% ; p$
$=.025)$. The results of comparison between BS occurrence and the variables work status and interest of dropping the course are showed in Table 2.

Table 2. Comparison among Burnout Syndrome occurrence and the variables Work Status and Interest of dropping the course. Rio Grande do Sul, Brazil, 2013

\begin{tabular}{|c|c|c|c|c|}
\hline & \multicolumn{4}{|c|}{ Burnout Syndrome } \\
\hline & & Yes N (\%) & No N (\%) & Total \\
\hline \multirow{3}{*}{ Work Status* } & Employed & 35 (6.15\%) & $130(22.85 \%)$ & $165(29.00 \%)$ \\
\hline & Unemployed & $106(18.63 \%)$ & 298 (52.37\%) & $404(71.00 \%)$ \\
\hline & Total & $141(24.78 \%)$ & $428(75.22 \%)$ & $569(100 \%)$ \\
\hline \multirow[t]{2}{*}{$p$ value** } & & .039 & & \\
\hline & Yes & $52(9.14 \%)$ & $129(22.67 \%)$ & $181(31.81 \%)$ \\
\hline \multirow[t]{2}{*}{ Interest of dropping the course* } & No & 89 (15.64\%) & 299 (52.55\%) & $388(68.19 \%)$ \\
\hline & Total & $141(24.78 \%)$ & 428 (75.22\%) & $569(100 \%)$ \\
\hline$p$ value $* *$ & & .027 & & \\
\hline
\end{tabular}

*One student did not answered the item. ${ }^{* *}$ Statistically significant difference (Fischer exact test).

Concerning the MBI-SS' subscales and the sociodemo- .0001) and who have not experience in healthcare (23.74\%, $p$ graphic and academic variables, we verify that high Cynicism $=.023$ ). The results of comparative analysis between BS' feaprevails in students aged between 20 and 24 years $(16.93 \%$, tures and the variables work status and interest of dropping $p=.047)$, who are enrolled in the first semester $(12.45 \%, p<$ the course are presented in Table 3 .

Table 3. Comparison among the levels of Emotional Exhaustion, Cynicism and Professional Efficacy and the variables work status and interest of dropping the course. Rio Grande do Sul, Brazil, 2013

\begin{tabular}{|c|c|c|c|c|c|c|c|c|c|c|}
\hline & & \multicolumn{8}{|c|}{ MBI-SS' Subscales } & \\
\hline & & \multicolumn{3}{|c|}{ Emotional Exhaustion } & \multicolumn{3}{|l|}{ Cynicism } & \multicolumn{2}{|c|}{ Professional Efficacy } & \\
\hline & & High & Low & & High & Low & & High & Low & \\
\hline \multirow{3}{*}{$\begin{array}{l}\text { Work } \\
\text { Status }\end{array}$} & Yes & $\begin{array}{l}17.03 \% \\
(n=95)\end{array}$ & $\begin{array}{l}11.11 \% \\
(n=62)\end{array}$ & $\begin{array}{l}28.14 \% \\
(\mathrm{n}=157)\end{array}$ & $\begin{array}{l}10.14 \% \\
(n=52)\end{array}$ & $\begin{array}{l}17.93 \% \\
(n=92)\end{array}$ & $\begin{array}{l}28.07 \% \\
(\mathrm{n}=144)\end{array}$ & $\begin{array}{l}2.64 \% \\
(\mathrm{n}=15)\end{array}$ & $\begin{array}{l}26.36 \% \\
(\mathrm{n}=150)\end{array}$ & $\begin{array}{l}29.00 \% \\
(\mathrm{n}=165)\end{array}$ \\
\hline & No & $\begin{array}{l}48.21 \% \\
(n=269)\end{array}$ & $\begin{array}{l}23.66 \% \\
(\mathrm{n}=132)\end{array}$ & $\begin{array}{l}71.86 \% \\
(\mathrm{n}=401)\end{array}$ & $\begin{array}{l}29.43 \% \\
(\mathrm{n}=151)\end{array}$ & $\begin{array}{l}42.50 \% \\
(n=218)\end{array}$ & $\begin{array}{l}71.93 \% \\
(\mathrm{n}=369)\end{array}$ & $\begin{array}{l}9.49 \% \\
(\mathrm{n}=54)\end{array}$ & $\begin{array}{l}61.51 \% \\
(\mathrm{n}=350)\end{array}$ & $\begin{array}{l}71.00 \% \\
(\mathrm{n}=404)\end{array}$ \\
\hline & Total & $\begin{array}{l}65.23 \% \\
(n=364)\end{array}$ & $\begin{array}{l}34.77 \% \\
(n=194)\end{array}$ & $\begin{array}{l}100 \% \\
\left(\mathrm{n}=558^{*}\right)\end{array}$ & $\begin{array}{l}39.57 \% \\
(n=203)\end{array}$ & $\begin{array}{l}60.43 \% \\
(n=310)\end{array}$ & $\begin{array}{l}100 \% \\
\left(\mathrm{n}=513^{*}\right)\end{array}$ & $\begin{array}{l}12.13 \% \\
(n=69)\end{array}$ & $\begin{array}{l}87.87 \% \\
(n=500)\end{array}$ & $\begin{array}{l}100 \% \\
(\mathrm{n}=569 *)\end{array}$ \\
\hline$p$ value & & & & $.026 * *$ & & & $.048 * *$ & & & $.042 * *$ \\
\hline \multirow{3}{*}{$\begin{array}{l}\text { Interest of } \\
\text { dropping } \\
\text { the course }\end{array}$} & Yes & $\begin{array}{l}24.37 \% \\
(\mathrm{n}=136)\end{array}$ & $\begin{array}{l}7.89 \% \\
(n=44)\end{array}$ & $\begin{array}{l}67.74 \% \\
(\mathrm{n}=378)\end{array}$ & $\begin{array}{l}12.28 \% \\
(n=63)\end{array}$ & $\begin{array}{l}20.66 \% \\
(n=106)\end{array}$ & $\begin{array}{l}32.94 \% \\
(\mathrm{n}=169)\end{array}$ & $\begin{array}{l}4.92 \% \\
(\mathrm{n}=28)\end{array}$ & $\begin{array}{l}26.89 \% \\
(\mathrm{n}=153)\end{array}$ & $\begin{array}{l}31.81 \% \\
(\mathrm{n}=181)\end{array}$ \\
\hline & No & $\begin{array}{l}40.86 \% \\
(n=228)\end{array}$ & $\begin{array}{l}26.88 \% \\
(n=150)\end{array}$ & $\begin{array}{l}32.26 \% \\
(\mathrm{n}=180)\end{array}$ & $\begin{array}{l}27.49 \% \\
(n=141)\end{array}$ & $\begin{array}{l}39.57 \% \\
(n=203)\end{array}$ & $\begin{array}{l}67.06 \% \\
(n=344)\end{array}$ & $\begin{array}{l}7.38 \% \\
(n=42)\end{array}$ & $\begin{array}{l}60.81 \% \\
(n=346)\end{array}$ & $\begin{array}{l}68.19 \% \\
(n=388)\end{array}$ \\
\hline & Total & $\begin{array}{l}65.23 \% \\
(n=364)\end{array}$ & $\begin{array}{l}34.77 \% \\
(\mathrm{n}=194)\end{array}$ & $\begin{array}{l}100 \% \\
\left(\mathrm{n}=558^{*}\right)\end{array}$ & $\begin{array}{l}39.77 \% \\
(n=204)\end{array}$ & $\begin{array}{l}60.23 \% \\
(n=309)\end{array}$ & $\begin{array}{l}100 \% \\
\left(\mathrm{n}=513^{*}\right)\end{array}$ & $\begin{array}{l}12.30 \% \\
(n=70)\end{array}$ & $\begin{array}{l}87.70 \% \\
(n=499)\end{array}$ & $\begin{array}{l}100 \% \\
(\mathrm{n}=569 *)\end{array}$ \\
\hline$p$ value & & & & $.000 * *$ & & & .055 & & & $.031 * *$ \\
\hline
\end{tabular}

*Remaining subjects did not answer the question. **Statistically significant difference.

\section{Discussion}

The BS was exclusively related to work environment at the beginning. ${ }^{[21]}$ However, nowadays, it is already known that it may be linked to sociodemographic features, to attitudes and to personality characteristics which are intrinsic to individuals and, thus, permeate the work relationships. ${ }^{[21,22]}$ Published by Sciedu Press
Therefore, the association of the academic and sociodemographic characteristics with the BS has been analyzed in different researches among students. ${ }^{[17,18]}$

In this sense, we verified that, among those Emotionally Exhausted, felling a poor Professional efficacy and suffering of $\mathrm{BS}$, there was predominance of unemployed individuals and 
who did not thought in dropping the course. In a research ${ }^{[23]}$ conducted with 2,222 medical students from United States, the authors verified that, among those with BS $(p<.05)$, $81.5 \%$ did not presented interest of dropping the course. However, several investigations ${ }^{[14,24]}$ have been assessed the relationship among the $\mathrm{BS}$ dimensions and the variables above, but without statistically significant correlation. In this context, not to work implies to spend time and energy primarily to academic activities and theirs demands. This is positive since the student has greater willingness to participate in events, courses and to meet the academic demands. However, to not work may be assessed, for the student, as the social (classmates and professor) withdrawal, the lacking of contact with the experiences provided by the work, as well as the loss of financial autonomy. About it, researcher points out that activity overload or lack of it (boredom and monotony in daily life) can cause Burnout. ${ }^{[21]}$ These factors can contribute to Emotional Exhaustion, an initial trait of the Syndrome. Concerning to the interest of dropping the course, we can say that, when the students of this investigations assess the academic context as exciding theirs cognitive resources, instead of using escape and avoidance strategies and abandoning the course, they seek confronting such situations. Consequently, if effective coping strategies are not selected, the occurrence of high emotional exhaustion and low professional efficacy, and, subsequently, the BS is possible. ${ }^{[19]}$

Besides, among students with BS, those enrolled in the first semester and who perform 10 disciplines were prevalent. In investigation ${ }^{[14]}$ did with students of the health area, a statistically significant and direct correlation was found between the variable number of disciplines and the Emotional Exhaustion $(r=.223 ; p<.01)$ and between this feature and the course semester $(r=.227 ; p<.01)$. These results are supported by assertive of that students, after leaving the high school and getting to college, need to deal with a new reality and to adopt an attitude of greater responsibility and autonomy. ${ }^{[14,16]}$ For nursing students, meeting a higher number of disciplines in first semester is required, i.e., students have to manage their time to meet the demands (tasks, readings and tests) of all the disciplines and of personal and social context (Family, friends, leisure and sport activities), what can lead them to stress at the beginning of the degree. ${ }^{[14]}$

Concerning the high Cynicism, this feature is prevalent among students aged between 20 and 24 years, unemployed, enrolled the first semester and who have not experience in the health area. In research with students of a technical nursing degree, ${ }^{[24]}$ authors observed that students who did not perform a professional activity showed a mean of Cynicism higher than others. About this, researchers believe that more idealistic individuals have a greater tendency to BS because they are so dedicated that they do everything necessary to achieve their goals. However, when it does not happen, the occurrence of Cynicism, with subsequently social and academic withdrawal, is possible. ${ }^{[21,22]}$ This is in accordance with the academic context because, when students getting to nursing degree, they are young people, unemployed and without experience in healthcare. So, they may idealize their academic training and their professional achievement concerning the degree they accessed. Over time, expectations may not be met, leading to the increased Cynicism. ${ }^{[14]}$

\section{Conclusions}

The BS Occurrence and of its constituents' features are higher among unemployed nursing students, who do not think in dropping the course, who are taking the first semester and performing 10 disciplines, aged between 20 and 24 years and without experience in health area. In this way, we state that certain demographic and academic characteristics of students contribute to BS occurrence. Thus, rethinking the distribution of disciplines throughout the semesters is necessary in order to reduce the academic activities overload in some degree periods. Also, providing a contact of the nursing students with the reality of their future profession since the beginning of degree should be considered due to possible differences between the ideal brought by the nursing students and the nursing work reality. Thus, strategies to minimize the risks of Burnout among nursing students have to be purposed.

As study limitation, we stand out the different analysis techniques used by researchers, which complicated the comparison between this study and the results of other investigations. Furthermore, few studies analyzed the academic and sociodemographic characteristics regarding to BS occurrence, being the relationships established between the characteristics and the MBI-SS' subscales.

\section{CONFlicts OF INTEREST Disclosure}

The authors declare that there is no conflict of interests regarding the publication of this article.

\section{REFERENCES}

[1] Costa ALS. Stress in nursing students: construction of determining factors. REME rev min enferm. 2007; 11(4): 414-9.
[2] Costa ALS, Polak C. Construction and validation of an instrument for the assessment of stress among nursing students (AEEE). Rev Esc Enferm USP. 2009; 43(Spec): 1017-26. 
[3] Killam LA, Mossey S, Montgomery P, et al. First year nursing students' viewpoints about compromised clinical safety. Nurse Educ. Today. 2013; 33(5): 475-80. PMid:22658213 https://doi.org/ $10.1016 / j$.nedt .2012 .05 .010

[4] Gibbons C. Stress, coping and burn-out in nursing students. Int J Nurs Stud. 2010 Oct; 47(10): 1299-309. PMid:20359710 https : //doi.org/10.1016/j.ijnurstu.2010.02.015

[5] Montgomery P, Mossey S, Killam L. Views of second year nursing students on impediments to safety in the clinical setting: Qmethodology. J Nurs Educ Pract. 2013; 3(8): 1-12.

[6] Basso Musso L, Vargas BA, Torres MB, et al. Factors derived from the intrahospitable laboratories that cause stress in infirmary students. Rev Latinoam Enferm. 2008; 16(5): 805-11. https: //doi.org/10.1590/S0104-11692008000500002

[7] Lazarus RS, Folkman S. Stress, appraisal, and coping. New York: Springer; 1984. 445 p.

[8] Divaris K, Polychronopoulou A, Taoufik K, et al. Stress and burnout in postgraduate dental education. Eur J Dent Educ. 2012 Feb; 16(1): 35-42. PMid:22251325

[9] Yusoff MS, Abdul Rahim AF, Baba AA, et al. Prevalence and associated factors of stress, anxiety and depression among prospective medical students. Asian J Psychiatr. 2013 Apr; 6(2): 12833. PMid:23466109 https://doi.org/10.1016/j.ajp. 2012 .09 .012

[10] Moreira DP, Furegato ARF. Stress and depression among students of the last semester in two nursing courses. Rev latinoam enferm. 2013; 21(Spec): 155-62.

[11] Juth V, Smyth JM, Santuzzi AM. How do you feel?: Self-esteem predicts affect, stress, social interaction, and symptom severity during daily life in patients with chronic illness. J Health Psychol. 2008 Oct; 13(7): 884-94. PMid:18809639 https ://doi.org/10.1177/13 59105308095062

[12] Lo R. A longitudinal study of perceived level of stress, coping and self-esteem of undergraduate nursing students: an Australian case study. J Adv Nurs. 2002 Jul; 39(2): 119-26. PMid:12100655 https://doi.org/10.1046/j.1365-2648.2000.02251.x
[13] Watson R, Deary I, Thompson D, et al. A study of stress and burnout in nursing students in Hong Kong: A questionnaire survey. Int J Nurs Stud. 2008 Oct; 45(10): 1534-42. PMid:18241870 https://doi.org/10.1016/j.ijnurstu.2007.11.003

[14] Carlotto MS, Nakamura AP, Câmara SG. Síndrome de Burnout em Estudantes universitários da Área da Saúde. Psico(Porto Alegre). 2006; 37(1): 57-62.

[15] Dyrbye LN, Thomas MR, Massie FS, et al. Burnout and suicidal ideation among U.S. medical students. Ann Intern Med. 2008 Sep 2; 149(5): 334-41.

[16] Campos JA, Jordani PC, Zucoloto ML, et al. Burnout syndrome among dental students. Rev Bras Epidemiol. 2012; 15(1): 155-65. PMid:22450501

[17] Carlotto MS, Câmara SG. Análise da produção científica sobre a Síndrome de Burnout no Brasil. Psico(Porto Alegre). 2008; 39(2): 152-58.

[18] Silva RM, Goulart CT, Guido LA. Síndrome de Burnout entre discentes da área da saúde- revisão integrativa da literatura. Av enferm. In press 2013.

[19] Carlotto MS, Câmara SG. Psychometric characteristics of the Maslach Burnout Inventory (MBI-SS) in Brazilian college students. Psico USF. 2006; 11(2): 167-73.

[20] Bailar J, Mosteller F. Medical users of statistics. Boston: Nejm Books; 1992. $347 \mathrm{p}$.

[21] Maslach C, Schaufeli WB, Leiter MP. Job Burnout. Ann. Rev. Psychol. 2001; 52(1): 397-422.

[22] Maslach C. What have we learned about burnout and health? Psychol Health. 2001 Sep; 16(5): 607-11. PMid:22804502 https: //doi.org/10.1080/08870440108405530

[23] Dyrbye LN, Thomas MR, Power DV, et al. Burnout and serious thoughts of dropping out of medical school: a multi-institutional study. Acad Med. 2010 Jan; 85(1): 94-102.

[24] Borges AMB, Carlotto MS. Burnout Syndrome and stress factors in students of a nursing technical course. Aletheia. 2004; (19): 45-56. 